\title{
Hydrothermal Preparation of Some Strontium Silicates
}

\author{
Elmer T. Carlson and Lansing S. Wells
}

\begin{abstract}
A study was made of the formation of hydrated strontium silicates under hydrothermal conditions. Seven hydrated compounds, believed to have the following compositions, were prepared: $\mathrm{SrO} \cdot 2 \mathrm{SiO}_{2} \cdot \mathrm{H}_{2} \mathrm{O}, \mathrm{SrO} \cdot \mathrm{SiO}_{2} \cdot \mathrm{H}_{2} \mathrm{O}, 2 \mathrm{SrO} \cdot 2 \mathrm{SiO}_{2} \cdot 3 \mathrm{H}_{2} \mathrm{O}, 3 \mathrm{SrO} \cdot 2 \mathrm{SiO}_{2} \cdot 3 \mathrm{H}_{2} \mathrm{O}$, $3 \mathrm{SrO} \cdot 2 \mathrm{SiO}_{2} \cdot 4 \mathrm{H}_{2} \mathrm{O}, 2 \mathrm{SrO} \cdot \mathrm{SiO}_{2} \cdot \mathrm{H}_{2} \mathrm{O}$, and $3 \mathrm{SrO} \cdot \mathrm{SiO}_{2} \cdot 2 \mathrm{H}_{2} \mathrm{O}$. The anhydrous compounds $\mathrm{SrO} \cdot \mathrm{SiO}_{2}$ and $2 \mathrm{SrO} \cdot \mathrm{SiO}_{2}$ were obtained by hydrothermal synthesis at temperatures as low as $124^{\circ}$ and $142^{\circ}$. C., respectively. No evidence was found that the anhydrous strontium silicates possess hydraulic binding properties. X-ray powder diffraction patterns and some optical data are given for the various hydrates, and possible relationships with the calcium silicates are discussed.
\end{abstract}

\section{Introduction}

During the course of an investigation of the possibility of preparing compounds of the hydrogarnet type described by Flint, McMurdie, and Wells [1], ${ }^{1}$ but with strontium substituted for calcium, it became necessary to identify the strontium silicates that were obtained in some of the experiments. In the absence of any specific data on the hydrated strontium silicates in the literature, a brief study was made of these compounds, and incidentally of the anhydrous silicates as well.

The anhydrous strontium silicates have been described by Eskola [2], who also worked out the phase diagram for the system $\mathrm{SrO}-\mathrm{SiO}_{2}$. The metaand orthosilicates, $\mathrm{SrSiO}_{3}$ and $\mathrm{Sr}_{2} \mathrm{SiO}_{4}$, respectivel were the only compounds found in this system. The metasilicate is apparently hexagonal, but forms a solid-solution series with $\alpha-\mathrm{CaSiO}_{3}$ (pseudowollastonite) which is monoclinic, and may therefore be monoclinic also. An X-ray diffraction pattern for the orthosilicate $\mathrm{Sr}_{2} \mathrm{SiO}_{4}$ has been published by O'Daniel and Tscheischwili [3]. Heats of formation of both silicates from the oxides have been reported by Nacken [4].

Preparation of tristrontium silicate has recently been reported by Nurse [5], who also gives the X-ray diffraction pattern. The compound was found not to be isomorphous with tricalcium silicate.

The hydrated strontium silicates appear to have been studied very little. Jordis and Kantner [6], obtained a precipitate approximating a 1:1 molar ratio by the reaction between $\mathrm{Na}_{2} \mathrm{SiO}_{3}$ and a soluble strontium compound, and it was assumed that the product was a hydrated metasilicate. Zhuravlev [7] reports that $\mathrm{Sr}_{2} \mathrm{SiO}_{4}$ possesses binding properties but gives no details as to the composition of the hydrated product.

\footnotetext{
1 Figures in brackets indicate the literature references at the end of this paper.
}

\section{Anhydrous Strontium Silicates}

Strontium metasilicate and orthosilicate were prepared from stoichiometric mixtures of $\mathrm{SrCO}_{3}$ and silicic acid (reagent grade) by heating for an hour in an electric furnace at about $1,425^{\circ} \mathrm{C}$. The composition was checked by analysis and found to be in close agreement with that calculated, but the microscope showed a little inhomogeneity in the metasilicate, and more in the orthosilicate.

The metasilicate preparation was considerably improved in homogeneity by fusion in an oxygen blast. This also increased the average crystal size. Crystals of better shape, however, were produced by hydrothermal means, as described later, and these were used for determination of optical characteristics. The interference figure indicated that the crystal is biaxial, with a very small optic axial angle; the symmetry, therefore, is not hexagonal. The refractive indices were found to be $\alpha=1.597, \gamma=1.637$, in good agreement with those given by Eskola [2]. The $\beta$-index is close to 1.597 .

An X-ray powder diffraction pattern ${ }^{2}$ for a hydrothermal preparation of $\mathrm{SrO} \cdot \mathrm{SiO}_{2}$ is given in table 1 . So far as known, no pattern for this compound has hitherto been published. The sample prepared by fusion of the mixed oxides gave a similar pattern except that many of the lines appeared to be double, triple, or quadruple, instead of forming well-defined single peaks. The significance of this difference is not known. It might conceivably indicate the existence of two forms having slightly different symmetry, but no evidence of any phase transformation was observed on differential thermal analysis of the preparation. This is in agreement with the findings of Eskola.

The X-ray pattern resembles that of $\alpha-\mathrm{CaO} \cdot \mathrm{SiO}_{2}$, indicating a relationship between the two as sug-

$2 \mathrm{X}$-ray diffraction patterns reported herein were made on an X-ray Geiger counter diffractometer, using $\mathrm{Cu} \mathrm{K} \boldsymbol{\alpha}_{1}$ radiation. 
TABLE 1. Interplanar spacings and relative intensitres of $X$-ray diffraction lines for the strontium silicates

\begin{tabular}{|c|c|c|c|c|c|c|c|}
\hline \multicolumn{2}{|c|}{$\mathrm{SrO} \cdot \mathrm{SiO}_{2}$} & \multicolumn{2}{|c|}{$\mathrm{SrO} \cdot 2 \mathrm{SiO}_{2} \cdot \mathrm{H}_{2} \mathrm{O}$} & \multicolumn{2}{|c|}{$\mathrm{SrO} \cdot \mathrm{SiO}_{2} \cdot \mathrm{H}_{2} \mathrm{O}$} & \multicolumn{2}{|c|}{$2 \mathrm{SrO} \cdot 2 \mathrm{SiO}_{2} \cdot 3 \mathrm{H}_{2} \mathrm{O}$} \\
\hline$d$ & $I$ & $d$ & $I$ & $d$ & $I$ & $d$ & $I$ \\
\hline 5.07 & 18 & 7. 02 & 12 & 5.25 & 16 & 7. 31 & 10 \\
\hline 3.57 & 65 & 4. 27 & 10 & 4. 26 & 100 & 4. 60 & 10 \\
\hline 3.37 & 38 & 3.67 & 32 & 3. 85 & 5 & 3.68 & 15 \\
\hline 2. 92 & 100 & 3. 44 & 100 & 3. 64 & 31 & 3. 55 & 15 \\
\hline 2. 53 & 17 & 3. 29 & 44 & 3. 27 & 71 & 3. 23 & 100 \\
\hline 2. 07 & 68 & 3. 16 & 10 & 2. 96 & 40 & 3.09 & 47 \\
\hline 1.914 & 33 & 3. 03 & 53 & 2. 80 & 39 & 2.64 & 15 \\
\hline 1. 783 & 10 & 2.78 & 19 & 2. 76 & 18 & 2. 41 & 20 \\
\hline 1. 759 & 3 & 2. 73 & 18 & 2. 72 & 31 & 2. 23 & 33 \\
\hline 1. 686 & 17 & 2.65 & 38 & 2. 63 & 39 & 2. 05 & 17 \\
\hline 1. 603 & 13 & 2. 31 & 7 & 2.57 & 35 & 1. 967 & 32 \\
\hline 1. 527 & 17 & 2. 24 & 22 & 2. 40 & 7 & 1. 932 & 19 \\
\hline 1. 460 & 17 & 2.17 & 34 & 2. 28 & 28 & 1. 770 & 9 \\
\hline 1. 350 & 5 & 2. 07 & 70 & 2. 18 & 26 & 1. 750 & 12 \\
\hline 1. 307 & 17 & 1.92 & 10 & 2. 13 & 10 & 1. 729 & 12 \\
\hline$-\ldots-$ & $-\ldots$ & 1. 87 & 13 & 2. 08 & 25 & 1. 632 & 11 \\
\hline -...... & ..... & 1. 83 & 18 & 1. 96 & 12 & 1.576 & 9 \\
\hline -...... & .... & 1.76 & 39 & 1. 93 & 31 & 1. 502 & 7 \\
\hline$-\ldots$ & .... & 1. 66 & 14 & 1.88 & 17 & 1. 475 & 7 \\
\hline -...... & .... & 1. 61 & 22 & 1.81 & 11 & & $\ldots$ \\
\hline -...- & -- & 1.52 & 18 & 1. 76 & 8 & ....... & .... \\
\hline -....- & -... & $-\ldots$ & & 1. 75 & 4 & ..... & .... \\
\hline ....... & -... & ........ & .... & 1. 66 & 9 & ... & ..... \\
\hline -..... & $\cdots$ & ...... & ....- & 1. 64 & 21 & ........ & -... \\
\hline$\cdots$ & -... & ....... & -... & 1. 56 & 7 & -...... & $\ldots$ \\
\hline - - - & $\cdots$ & & .... & 1. 50 & 9 & -....... & ...... \\
\hline -..... & .... & ....... & $\ldots$ & 1. 44 & 11 & ...... & .... \\
\hline -..-- & $-\cdots$ & ...... & -... & 1. 42 & 9 & -...... & .... \\
\hline -n.-.- & $\cdots$ & -..... & -.... & 1. 38 & 11 & & $\ldots$ \\
\hline \multicolumn{2}{|c|}{$3 \mathrm{SiO}_{2} \cdot 2 \mathrm{SiO}_{2} \cdot 3 \mathrm{H}_{2} \mathrm{O}$} & \multicolumn{2}{|c|}{$3 \mathrm{SiO}_{2} \cdot 2 \mathrm{SiO}_{2} \cdot 4 \mathrm{H}_{2} \mathrm{O}$} & \multicolumn{2}{|c|}{$2 \mathrm{SrO} \cdot \mathrm{SiO}_{2} \cdot \mathrm{H}_{2} \mathrm{O}$} & \multicolumn{2}{|c|}{$3 \mathrm{SrO} \cdot \mathrm{SiO}_{2} \cdot 2 \mathrm{H}_{2} \mathrm{O}$} \\
\hline 6.73 & 50 & 4. 89 & 50 & 9. 60 & 13 & 10. 13 & 40 \\
\hline 6.11 & 7 & 3.73 & 95 & 5.74 & 8 & 7.54 & 9 \\
\hline 4. 25 & 42 & 3. 53 & 5 & 5. 02 & 17 & 7.03 & 7 \\
\hline 3.68 & 5 & 2. 96 & 39 & 4.75 & 12 & 5. 05 & 20 \\
\hline 3.49 & 14 & 2. 76 & 100 & 4. 01 & 16 & 4. 79 & 22 \\
\hline 3. 33 & 65 & 2.64 & 29 & 3. 83 & 9 & 4. 68 & 7 \\
\hline 3.16 & 13 & 2.44 & 12 & 3. 58 & 79 & 4. 53 & 23 \\
\hline 3.10 & 11 & 2. 32 & 32 & 3. 50 & 10 & 4. 44 & 10 \\
\hline 2.89 & 100 & 2. 07 & 21 & 3. 45 & 10 & 3. 69 & 25 \\
\hline 2.80 & 10 & 1.971 & 21 & 3. 35 & 38 & 3. 51 & 25 \\
\hline 2.76 & 7 & 1.906 & 62 & 3. 24 & 10 & 3. 44 & 7 \\
\hline 2. 69 & 4 & 1.810 & 13 & 3. 17 & 100 & 3. 37 & 23 \\
\hline 2. 50 & 7 & 1. 743 & 6 & 3. 00 & 32 & 3. 22 & 26 \\
\hline 2. 41 & 23 & 1. 669 & 15 & 2. 92 & 60 & 3. 11 & 100 \\
\hline 2. 26 & 7 & 1. 545 & 12 & 2. 84 & 42 & 3. 04 & 35 \\
\hline 2. 21 & 20 & 1. 483 & 13 & 2. 81 & 22 & 2. 98 & 37 \\
\hline 2.18 & 9 & 1. 377 & 13 & 2.76 & 22 & 2.95 & 15 \\
\hline 2.11 & 14 & 1. 332 & 11 & 2.55 & 17 & 2. 75 & $\begin{array}{l}19 \\
19\end{array}$ \\
\hline 2. 05 & 16 & 1. 220 & 10 & 2.51 & 10 & 2. 61 & 32 \\
\hline 2. 02 & 23 & & $\ldots$ & 2.45 & 27 & 2. 49 & 15 \\
\hline 1. 975 & 18 & . & $\ldots$ & 231 & 7 & 2. 39 & 8 \\
\hline 1.899 & 10) & ..... & .... & 2.26 & $\dot{9}$ & 2. 34 & $\begin{array}{l}8 \\
5\end{array}$ \\
\hline 1. 866 & 20 & . & 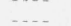 & 2. 13 & 14 & 2. 13 & 41 \\
\hline 1.778 & 14 & . & .... & 2. 09 & 15 & 2. 05 & 15 \\
\hline 1.676 & 12 & $\ldots \ldots$ & $\ldots$. & 2. 05 & 37 & 2.01 & 20 \\
\hline 1. 661 & 11 & $\ldots$ & .... & 2.01 & 10 & 1. 971 & 33 \\
\hline 1. 572 & 8 & ....... & $\ldots .$. & 1. 97 & 20 & 1. 932 & 10 \\
\hline 1. 454 & 8 & $\ldots$ & $\ldots .$. & 1. 94 & 10 & 1. 845 & 18 \\
\hline 1.422 & 5 & & $\ldots$ & $\begin{array}{l}1.90 \\
1.90\end{array}$ & 37 & 1.806 & 12 \\
\hline & & & & $\begin{array}{l}\text { 1. } 82 \\
\text { lo }\end{array}$ & 17 & $\begin{array}{l}1.800 \\
1.776\end{array}$ & 8 \\
\hline$\ldots$ & $\ldots$ & & & 1. 73 & 15 & $\begin{array}{l}1.736 \\
\text { - }\end{array}$ & 11 \\
\hline & & & & 1. 60 & 10 & 1. 685 & 18 \\
\hline$\ldots$. & $\ldots$ & & $\alpha$ & 1. 53 & 9 & 1.637 & 11 \\
\hline . & ..... & ....... & $\ldots$. & 1. 43 & 11 & 1. 602 & 8 \\
\hline & & - & $\cdots$ & & .... & 1. 572 & 9 \\
\hline
\end{tabular}

gested by Eskola. This is supported by the similarity in optical properties.

No attempt was made to prepare anhydrous tristrontium silicate.

\section{Hydrated Strontium Silicates Prepared at Atmospheric Pressure}

\section{1. $3 \mathrm{SrO} \cdot 2 \mathrm{SiO}_{2} \cdot 3 \mathrm{H}_{2} \mathrm{O}$}

The compound $3 \mathrm{SrO} \cdot 2 \mathrm{SiO}_{2} \cdot 3 \mathrm{H}_{2} \mathrm{O}$ was obtained by slowly adding sodium silicate solution $(12 \mathrm{~g}$ $\mathrm{Na}_{2} \mathrm{SiO}_{3} \cdot 9 \mathrm{H}_{2} \mathrm{O}$ in a small amount of water) to a boiling solution of strontium hydroxide $(30 \mathrm{~g}$ of the octa- hydrate in about $800 \mathrm{ml}$ of water). Boiling was continued for an hour, and the mixture was kept on the steam bath overnight. The precipitate, apparently gelatinous at first, became completely crystalline. The crystals were very small, acicular or lath-shaped and slightly birefringent, with negative elongation. From the analysis of two separate preparations, the molar ratio was calculated to be $\mathrm{SrO}: \mathrm{SiO}_{2}: \mathrm{H}_{2} \mathrm{O}=$ $2.96: 2: 3.26^{3}$ for the one, $2.97: 2: 3.17$ for the other. From this the formula $3 \mathrm{SrO} \cdot 2 \mathrm{SiO}_{2} \cdot 3 \mathrm{H}_{2} \mathrm{O}$ is assumed to be correct. X-ray diffraction data are given in table 1.

Larger crystals of the same compound were subsequently obtained hydrothermally. Some of these are shown in figure 1. They were found to be biaxial, positive, with refractive indices: $\alpha=1.602$; $\beta=1.602 ; \gamma=1.614$. The optic axial angle was very small.

Differential thermal analysis of this compound shows a large endothermic effect at about $340^{\circ} \mathrm{C}$, corresponding to dehydration. Two small exothermic effects occur at $820^{\circ}$ and $890^{\circ} \mathrm{C}$, suggesting the possibility that the loss of water involves a break-down to the oxides, which subsequently recombine to form anhydrous silicates.

During the preparation of this material, the reactants were in such proportion as to provide a considerable excess of $\mathrm{Sr}(\mathrm{OH})_{2}$, hence it may be assumed that no more basic hydrate may be formed by this method. An attempt to prepare a less basic compound by reducing the $\mathrm{Sr}(\mathrm{OH})_{2}$ concentration to the same molar strength as the $\mathrm{Na}_{2} \mathrm{SiO}_{3}$ resulted in an amorphous product.

\section{2. $3 \mathrm{SrO} \cdot 2 \mathrm{SiO}_{2} \cdot 4 \mathrm{H}_{2} \mathrm{O}$}

By boiling a mixture of silica gel and strontium hydroxide solution for half an hour, a different compound was obtained. This consisted of distinctive dendritic or feathershaped crystals with moderate birefringence. From chemical analysis, the molar ratio $\mathrm{SrO}: \mathrm{SiO}_{2}: \mathrm{H}_{2} \mathrm{O}$ was calculated to be $3.04: 2: 4.06$ from which it was concluded that the composition was $3 \mathrm{SrO} \cdot 2 \mathrm{SiO}_{2} \cdot 4 \mathrm{H}_{2} \mathrm{O}$. The differential heating curve on this material is similar to that of the $3: 2: 3$ hydrate except that the dehydration break is double, with the first peak at $230^{\circ}$ and a larger one at $300^{\circ} \mathrm{C}$, indicating that the water is driven off in two stages. The exothermic breaks occur at $800^{\circ}$ and $890^{\circ}$. It is concluded that the $3: 2: 4$ hydrate first loses one molecule of water, forming the $3: 2: 3$ hydrate, which is then decomposed on further heating. This conclusion is supported by results of hydrothermal experiments to be described later.

The $3: 2: 4$ compound was also obtained in a large number of hydrothermal experiments. Figure 2 is a photomicrograph of one such preparation; the crystals are larger than those obtained by boiling, but exhibit the same habit of growth.

${ }^{3}$ The percentage of loss in weight on ignition at $1,100^{\circ}$ was taken as the percent age of $\mathrm{H}_{2} \mathrm{O}$, with no correction for the slight amount of carbonate that may be assumed to have been formed from the $\mathrm{CO}_{2}$ in the water and air in the reaction vessel. 


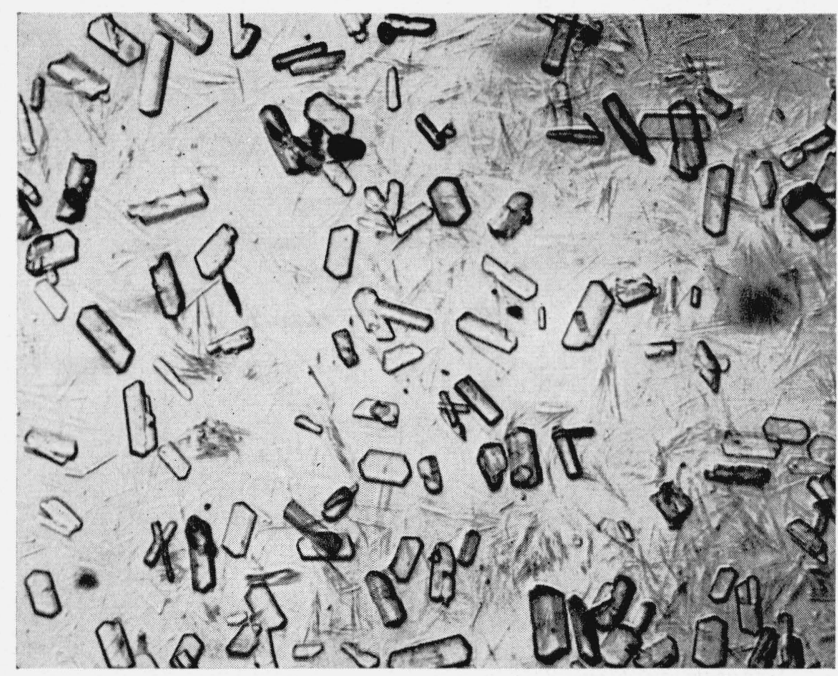

Figure 1. Crystals of $3 \mathrm{SrO} \cdot 2 \mathrm{SiO}_{2} \cdot 3 \mathrm{H}_{2} \mathrm{O}$ (prismatic crystals), together with $3 \mathrm{SrO} \cdot \mathrm{SiO}_{2} \cdot \mathrm{H}_{2} \mathrm{O}$ (faint needles).

Magnification, $\times 190$.

Comparison of the X-ray diffraction patterns of over 20 preparations in which this compound was identified showed that they were about equally divided into 2 types. The pattern given in table 1 is typical of the group arbitrarily designated type 1 . In type 2 about half the lines were in substantially the same positions as in type 1 , the rest being shifted distinctly to the right (that is, toward smaller spacings), except for the line at 2.07 , which was shifted to 2.09. The significance of this is unknown. No correlation was observed between the X-ray pattern type and chemical analysis, presence of other phases, temperature of reaction, or refractive indices.

The indices also varied among the several preparations, but were difficult to determine precisely. The high index ranged from 1.627 to 1.637 ; the low index from 1.595 to 1.617 .

The same compound was obtained by heating silica gel with strontium hydroxide solution on a steam bath overnight (temperature about $75^{\circ} \mathrm{C}$ ), but the reaction was incomplete. Similar reaction mixtures held at $30^{\circ}$ and at $50^{\circ}$ for several months failed to develop any of the $3: 2: 4$ compound. On the other hand, the product was not entirely amorphous in either case. An X-ray diffraction pattern of the material from the $30^{\circ}$ test showed two rather diffuse lines. The $50^{\circ}$ product showed the same lines somewhat sharper with the addition of a few others. Apparently conversion was only partial, and the crystalline product has not been identified.

\section{Hydrothermal Reactions}

\section{1. Procedure}

Strontium hydroxide and silica gel were the raw materials for most of the hydrothermal experiments. The strontium hydroxide was "CP" grade and contained a variable amount of carbonate, which was

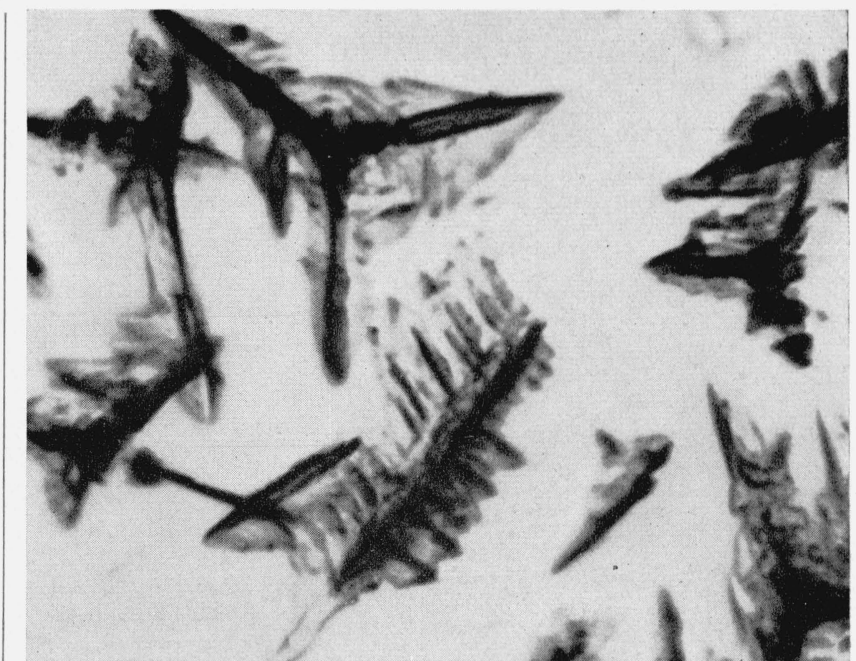

Figure 2. Dendritic crystals of $3 \mathrm{SrO} \cdot 2 \mathrm{SiO}_{2} \cdot 4 \mathrm{H}_{2} \mathrm{O}$.

Magnification, $\times 700$.

removed by a process of solution, filtration, and recrystallization. Four different lots of silica were used: (I) reagent grade "Silicic Acid" containing 0.16 percent of nonvolatile residue after treatment with hydrofluoric acid; (II) a commercial silica gel, extremely fine and highly reactive but containing 3 percent of nonvolatile residue, including 1.17 percent of $\mathrm{Na}_{2} \mathrm{O}$; (III) a commercial silica gel containing 0.45 percent of nonvolatile residue; (IV) a specially purified gal, relatively coarse and unreactive, containing 0.10 percent of nonvolatile residue. For other experiments, some of the strontium silicates were used as starting materials. The materials were mixed in the desired proportions, and a small quantity (usually about a gram), together with 1 to $2 \mathrm{ml} \mathrm{H}_{2} \mathrm{O}$, was placed in a small platinum crucible supported in a pressure bomb containing sufficient water to maintain a liquid phase at the desired temperature. The bomb was then kept in a controlled furnace for a period of several days. After the warming-up period, the maximum deviation from the reported temperature was about $\pm 2^{\circ} \mathrm{C}$. Upon removal from the furnace, the bomb was allowed to cool in front of a fan for about half an hour. Because of the slowness of the reactions, no significant changes are believed to have occurred during this cooling period.

\subsection{Results of Hydrothermal Experiments \\ a. General}

Table 2 gives the results of a number of hydrothermal experiments, selected to present the essential information. Confirmatory or supporting data have been omitted in the interest of brevity. The experiments are tabulated in the order of increasing basicity of reacting mixture, and will be discussed in that order. There are certain observations, however, that apply to the study as a whole. 
TABLE 2. Results of hydrothermal experiments in the system $\mathrm{SrO}-\mathrm{SiO}_{2}-\mathrm{H}_{2} \mathrm{O}$

\begin{tabular}{|c|c|c|c|c|}
\hline $\begin{array}{l}\text { Expt. } \\
\text { No. }\end{array}$ & Starting material 1 & $\begin{array}{l}\text { Tem- } \\
\text { pera- } \\
\text { ture }\end{array}$ & Time & Product \\
\hline $\begin{array}{r}1 \\
2 \\
3 \\
4 \\
5 \\
6 \\
7 \\
8 \\
9 \\
10 \\
11 \\
12 \\
13 \\
14 \\
15 \\
16 \\
17 \\
18 \\
19 \\
20 \\
21 \\
22 \\
23 \\
24 \\
25 \\
26 \\
27 \\
28 \\
29 \\
30 \\
31 \\
32 \\
33 \\
34 \\
35 \\
36 \\
37 \\
38 \\
39 \\
40 \\
41 \\
42 \\
43 \\
44 \\
45 \\
46 \\
47 \\
48 \\
49 \\
50 \\
51 \\
52 \\
53 \\
54 \\
55 \\
56 \\
57 \\
58 \\
59 \\
60 \\
61 \\
62 \\
63 \\
64 \\
65 \\
66 \\
67 \\
68 \\
69 \\
70 \\
71 \\
72 \\
73 \\
74 \\
75 \\
76 \\
77 \\
78 \\
79 \\
80\end{array}$ & 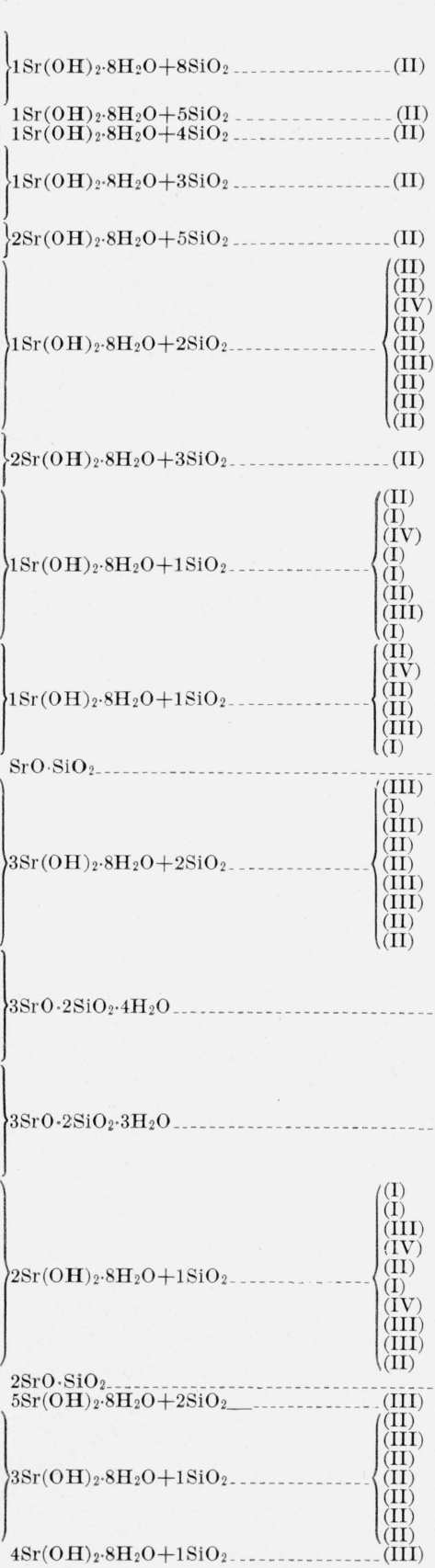 & 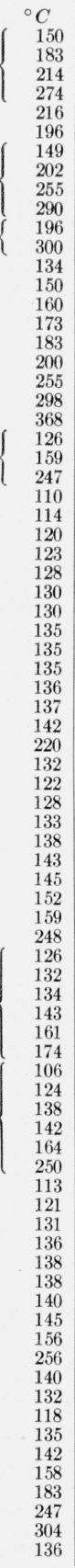 & 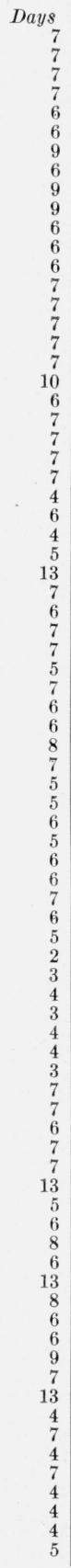 & 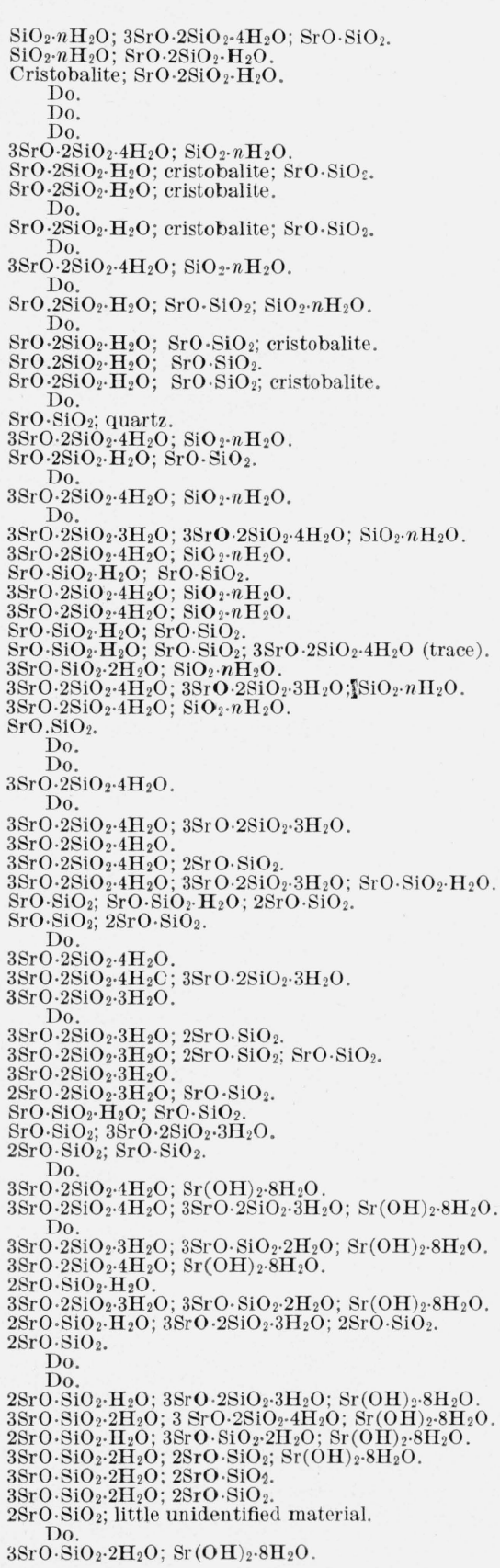 \\
\hline
\end{tabular}

${ }^{1}$ Roman numerals indicate the particular lot of silica gel used: (I) Reagent silicic acid, (II) A commercial gel of high fineness and low purity, (III) A commercial gel of medium fineness and purity, (IV) A rather coarse gel of high purity.

The system was found to be rather complex. In addition to the 2 hydrated silicates described above, 5 new compounds were observed. All have been tentatively assigned formulas, but the compositions of some are not definitely established. This is due to the failure to obtain pure preparations. It may be that some of the compounds are metastable under all conditions, and have only a transitory existence.

Another notable aspect of the system is that the hydrated compounds occur only at relatively low temperatures. It is noteworthy that anhydrous compounds were formed hydrothermally at tempera- 
tures as low as $124^{\circ}$, and that most of the hydrates decomposed below $150^{\circ}$. Because of the narrow range of stability, relatively small fluctuations in temperature or in rate of heating may have affected the results.

It will be noted that the results are not always in accord. Different products are sometimes obtained under apparently identical conditions. It was observed that different types of silica may give different results. For example, the compound $3 \mathrm{SrO} \cdot \mathrm{SiO}_{2} \cdot 2 \mathrm{H}_{2} \mathrm{O}$ appeared unexpectedly in a $2: 1$ mixture (experiment 64) in which the relatively coarse-grained silica gel IV was used. In this case it may be assumed that the low reactivity of the silica resulted in a temporary excess of strontium hydroxide above the calculated ratio. In other cases the differences are harder to explain. The type of silica used in each case is recorded in the table, although no attempt was made to study their differences systematically.

At temperatures slightly above $100^{\circ}$, the primary reaction product in all cases appeared to be $3 \mathrm{SrO} \cdot 2 \mathrm{SiO}_{2} \cdot 4 \mathrm{H}_{2} \mathrm{O}$, irrespective of the proportion in which the oxides were present. Crystals having the same distinctive shape were frequently observed in reaction products that had been held at much higher temperatures, but it was found by X-ray diffraction and refractive index determinations that these had undergone decomposition without losing their over-all appearance. It must be assumed that the hydrate was formed initially, possibly during the warming-up period, and subsequently was decomposed at the higher temperatures.

Anhydrous strontium metasilicate $\left(\mathrm{SrO} \cdot \mathrm{SiO}_{2}\right)$ and orthosilicate $\left(2 \mathrm{SrO} \cdot \mathrm{SiO}_{2}\right)$ were formed at temperatures as low as $124^{\circ}$ and $142^{\circ}$, respectively. In general, there was evidence of intermediate formation of one or more of the hydrates, but the metasilicate occasionally appeared in the form of spherical aggregates, as if it had formed directly at the surface of the silica grains. More often it occurred as welldefined tabular crystals of hexagonal shape, as shown in figure 3. These were found to be optically biaxial, with a very small optic axial angle. The compound thus is shown to be pseudohexagonal, as suggested by Eskola [2].

The rest of the products were obtained over a narrower range of oxide ratio in the reaction mixture, and will be considered in the following sections in relation to that ratio.

\section{b. Mixtures Less Basic Than $1 \mathrm{SrO}: 1 \mathrm{SiO}_{2}$}

Hydrothermal treatment of mixtures ranging in $\mathrm{SrO}: \mathrm{SiO}_{2}$ ratio from 1:8 to $2: 3$ initially produced the $3: 2: 4$ hydrate. Continued treatment resulted in anhydrous $\mathrm{SrO} \cdot \mathrm{SiO}_{2}$, together with an unknown compound. In the highly siliceous mixtures the excess silica was converted to cristobalite above $180^{\circ}$, and to quartz in one case at $368^{\circ}$. The new compound was first detected by means of its X-ray diffraction pattern. It was subsequently observed under the microscope in the form of extremely fine, round, nearly isotropic grains, usually in relatively

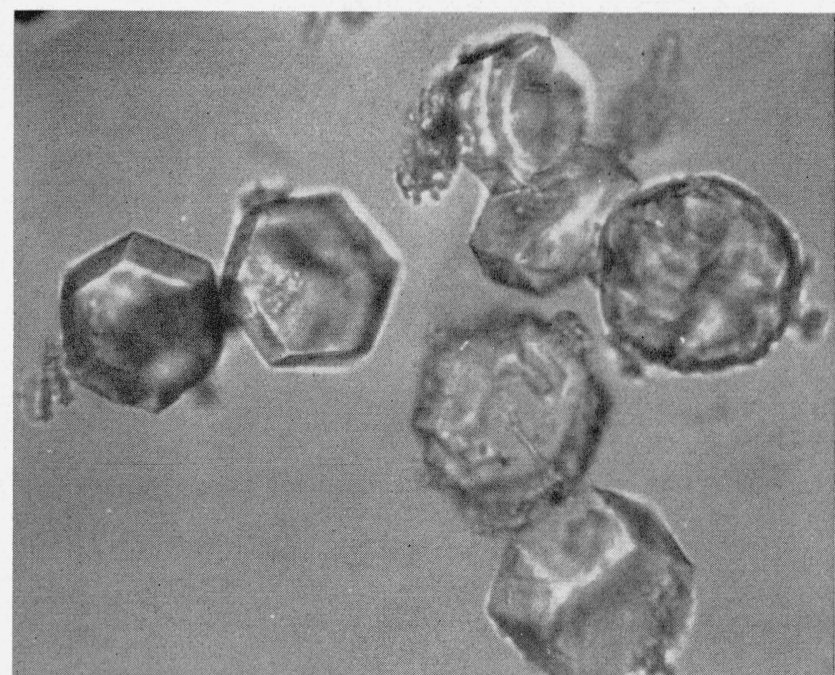

Figure 3. Crystals of $\mathrm{SrO} \cdot \mathrm{SiO}_{2}$, formed under hydrothermal conditions.

Magnification, $\times 700$.

large aggregates. The mean index of refraction appeared to be about 1.574 , but this figure is subject to considerable uncertainty. Many of the grains seemed to have a much lower index, but this is believed to have been due to a shell of cristobalite surrounding a core of the silicate. The existence of solid solution appears unlikely in view of the constancy of the X-ray pattern.

Because the new compound was not obtained pure, it was necessary to arrive at its composition indirectly. Mixtures of $1 \mathrm{SrO}: 2 \mathrm{SiO}_{2}$ yielded the new phase together with small amounts of both cristobalite and $\mathrm{SrO} \cdot \mathrm{SiO}_{2}$. Increasing the strontium to a ratio $2 \mathrm{SrO}: 3 \mathrm{SiO}_{2}$ resulted in the new phase plus $\mathrm{SrO} \cdot \mathrm{SiO}_{2}$ but no cristobalite, indicating that the compound in question is richer in $\mathrm{SiO}_{2}$ than the reaction mixture. For mixtures more siliceous than $1 \mathrm{SrO}: 2 \mathrm{SiO}_{2}$, the results are less easy to interpret. $\mathrm{SrO} \cdot \mathrm{SiO}_{2}$ appeared in $1: 3$ mixtures, and even in one instance in a $1: 8$ mixture, at $150^{\circ}$. Bearing in mind the fact mentioned above, that the hydrate $3 \mathrm{SrO} \cdot 2 \mathrm{SiO}_{2} \cdot 4 \mathrm{H}_{2} \mathrm{O}$ is formed initially even in the highly siliceous mixtures, it is possible that the subsequent decomposition of this hydrate leads most readily to the formation of the anhydrous metasilicate. The latter is known to be relatively stable and, once formed, would have little tendency to react further; hence, it might occur in compositions far removed from a $1: 1$ ratio. Both cristobalite and $\mathrm{SrO} \cdot \mathrm{SiO}_{2}$ were formed in small amounts from the $2 \mathrm{SrO}: 5 \mathrm{SiO}_{2}$ mixtures, but the proportion of cristobalite was estimated to be higher than that of the $\mathrm{SrO} \cdot \mathrm{SiO}_{2}$. Thus the ratio for the new compound appears to lie between $2: 5$ and $2: 3$; it is therefore assumed to be $1: 2$. Ignition loss determinations on several preparations indicated an average content of about 0.7 mole of water. Allowing for the anhydrous impurities present, the new compound is thus believed to have the composition $\mathrm{SrO} \cdot 2 \mathrm{SiO}_{2} \cdot \mathrm{H}_{2} \mathrm{O}$. 


\section{c. Molar Ratio 1SrO: $1 \mathrm{SiO}$}

Equimolar mixtures of strontium hydroxide and silica gel, like the more highly siliceous mixtures, reacted to form $3 \mathrm{SrO} \cdot 2 \mathrm{SiO}_{2} \cdot 4 \mathrm{H}_{2} \mathrm{O}$ at the lowest temperatures used $\left(110^{\circ}\right.$ to $\left.114^{\circ}\right)$. At $142^{\circ}$, and higher, the reaction product was always the anhydrous metasilicate, $\mathrm{SrO} \cdot \mathrm{SiO}_{2}$. At intermediate temperatures, the nature of the product appeared to depend on the type of silica gel used, but the results were not always consistent even with a single type of gel. For example, table 2 , experiments 30,35 , and 36 , reveals that both $3 \mathrm{SrO} \cdot 2 \mathrm{SiO}_{2} \cdot 4 \mathrm{H}_{2} \mathrm{O}$ and $3 \mathrm{SrO} \cdot 2 \mathrm{SiO}_{2} \cdot 3 \mathrm{H}_{2} \mathrm{O}$ were formed at $136^{\circ}$ but only the former at $130^{\circ}$ and $137^{\circ}$ in mixtures containing gel II. The trihydrate was formed from gel IV at $120^{\circ}$ (experiment 27), but not from gel I at any temperature. The formation of the highly basic compound, $3 \mathrm{SrO} \cdot \mathrm{SiO} \cdot 2 \mathrm{H}_{2} \mathrm{O}$, in experiment 34 has already been mentioned.

In experiments 29,32, and 33 a new phase appeared. This consisted of minute flakes with low birefringence and a mean index of 1.604. Repeated efforts to produce this compound reasonably free from other phases met with failure. 'The best preparation, No. 33, contained 0.99 mole of $\mathrm{H}_{2} \mathrm{O}$ per mole of $\mathrm{SrO} \cdot \mathrm{SiO}_{2}$, while No. 32, with a higher proportion of anhydrous material, contained 0.74 mole of $\mathrm{H}_{2} \mathrm{O}$. On the basis of this meager evidence the formula $\mathrm{SrO} \cdot \mathrm{SiO}_{2} \cdot \mathrm{H}_{2} \mathrm{O}$ has been assigned to this compound. The $\mathrm{X}$-ray pattern is given in table 1.

Treatment of anhydrous $\mathrm{SrO} \cdot \mathrm{SiO}_{2}$ at $132^{\circ}$ left the material apparently unchanged, although this is within the temperature range in which the various hydrates were formed from the hydrated oxides.

\section{d. Molar Ratio $3 \mathrm{SrO}: 2 \mathrm{SiO}_{2}$}

Mixtures of strontium hydroxide and silica gel in $3: 2$ ratio reacted as did the equimolar mixtures, except that the increase in $\mathrm{SrO}$ resulted in the formation of the anhydrous orthosilicate, $2 \mathrm{SrO} \cdot \mathrm{SiO}_{2}$, at the higher temperatures. This compound always appeared as irregular masses of small particles, often pseudomorphic atter $3 \mathrm{SrO} \cdot 2 \mathrm{SiO}_{2} \cdot 4 \mathrm{H}_{2} \mathrm{O}$. Unlike the metasilicate, it was never found as well-defined crystals. In this, as in the preceding series, the results within a small temperature range are varied and inconsistent.

In two series of experiments the starting materials were the $3: 2: 4$ and $3: 2: 3$ hydrates described above. From the results in table 2 , it may be seen that the $3: 2: 4$ hydrate was converted to the trihydrate at temperatures of $132^{\circ} \mathrm{C}$ and higher. For reasons unknown, this result was not consistently obtained from mixtures of the hydrated oxides in the same molar ratio. At $161^{\circ}$ and above, anhydrous compounds were formed.

The trihydrate behaved differently in that two additional hydrates were formed, at $124^{\circ}$ and $138^{\circ}$, respectively. In the latter case, the compound was $\mathrm{SrO} \cdot \mathrm{SiO}_{2} \cdot \mathrm{H}_{2} \mathrm{O}$, described in the previous section. The new phase formed at $124^{\circ}$ proved to be very elusive. It was obtained in small amounts in a few other experiments not included in the table, but never free of other phases. It appeared in the form of very fine needles with an average refractive index about 1.60. It could be distinguished from $\mathrm{SrO} \cdot \mathrm{SiO}_{2}$. $\mathrm{H}_{2} \mathrm{O}$ only by its X-ray diffraction pattern (see table 1). Although this compound was not obtained hydrothermally sufficiently pure for chemical analysis, a preparation obtained at a lower temperature, by a method to be described later, was found to have the following oxide ratio: $\mathrm{SrO}: \mathrm{SiO}_{2}: \mathrm{H}_{2} \mathrm{O}=0.96: 1: 1.44$. The formula $2 \mathrm{SrO} \cdot 2 \mathrm{SiO}_{2} \cdot 3 \mathrm{H}_{2} \mathrm{O}$ is suggested as a possibility on the basis of this analysis.

It is worthy of note that although the $3: 2: 4$ hydrate was converted to the $3: 2: 3$ by raising the temperature to $132^{\circ}$ or higher, the reverse reaction was not obtained by holding the $3: 2: 3$ hydrate at $106^{\circ}$ (experiment 55).

\section{e. Molar Ratio $2 \mathrm{SrO}: 1 \mathrm{SiO}_{2}$ and $5 \mathrm{SrO}_{2} \mathrm{SiO}_{2}$}

An increase in $\mathrm{SrO}$ to the 2:1 ratio gave rise to two new hydrated compounds. One of these, the tristrontium compound, will be discussed in the next section. The other appeared, along with other crystalline products, at $132^{\circ}$ to $148^{\circ} \mathrm{C}$. Analyses of preparations 66 and 72 , which appeared to be most nearly homogeneous, gave the following molar ratios, respectively : $\mathrm{SrO}: \mathrm{SiO}_{2}: \mathrm{H}_{2} \mathrm{O}=1.86: 1: 0.98$ and 1.86:1:1.09. The formula $2 \mathrm{SrO} \cdot \mathrm{SiO}_{2} \cdot \mathrm{H}_{2} \mathrm{O}$ fits the data reasonably well.

This compound occurred as small lath-shaped crystals, with parallel extinction and negative elongation. It is biaxial positive in character, with low and high indices of 1.638 and 1.641, respectively. The $\mathrm{X}$-ray powder diffraction pattern is given in table 1 .

At $156^{\circ}$ and above, the anhydrous orthosilicate, $2 \mathrm{SrO} \cdot \mathrm{SiO}_{2}$, was formed. Attempts to reverse the reaction by holding the anhydrous compound at $140^{\circ}$ and below were unsuccessful.

\section{f. Molar Ratio 3SrO: $1 \mathrm{SiO}_{2}$ and Higheri}

Mixtures of strontium hydroxide and silica gel in $3: 1$ ratio produced a new compound that has been referred to in the previous section. As in the case of the other hydrothermal preparations, it was always contaminated with one or more other phases. Analyses of three preparations gave the following $\mathrm{SrO}: \mathrm{SiO}_{2}: \mathrm{H}_{2} \mathrm{O}$ ratios: No. 76, 2.9:1:2.2; No. 75, $2.7: 1: 1.7$; No. 80, 3.1:1:2.7. The first of these preparations contained a small amount of $2 \mathrm{SrO} \cdot \mathrm{SiO}_{2}$, the second somewhat more. The third was prepared from an original 4:1 mixture and contained a small amount of $\mathrm{Sr}(\mathrm{OH})_{2} \cdot 8 \mathrm{H}_{2} \mathrm{O}$, which probably accounts for the higher $\mathrm{H}_{2} \mathrm{O}$ content. On the basis of these analyses, it is concluded that the compound has the composition $3 \mathrm{SrO} \cdot \mathrm{SiO}_{2} \cdot 2 \mathrm{H}_{2} \mathrm{O}$. It was observed as very thin needles or plates (see fig. 1), often joined in spherulites. They were birefringent, with indices $\alpha=1.575, \gamma=1.595$, and showed parallel extinction and positive elongation. The X-ray diffraction pattern given in table 1 is a composite of five patterns on different preparations. 
This hydrate was formed together with $3 \mathrm{SrO} \cdot 2 \mathrm{SiO}_{2}$. $4 \mathrm{H}_{2} \mathrm{O}$ at $118^{\circ} \mathrm{C}$. At higher temperatures the less basic hydrate was changed to the anhydrous $2 \mathrm{SrO}$. $\mathrm{SiO}_{2}$, which frequently retained the peculiar shape of the original crystals. The tristrontium compound was formed at temperatures as high as $183^{\circ}$, but at $247^{\circ}$ and above only $2 \mathrm{SrO} \cdot \mathrm{SiO}_{2}$ could be identified.

A sample of the tristrontium silicate hydrate, after being heated to $1,200^{\circ}$, was found to have decomposed to $2 \mathrm{SrO} \cdot \mathrm{SiO}_{2}$ and $\mathrm{SrO}$.

\section{Action of Water on the Strontium Silicates}

The behavior of the various strontium silicates in the presence of water was not studied thoroughly in this investigation, but because of the possibility of hydraulic properties [7] it was considered desirable to make a few exploratory tests.

A small quantity of the anhydrous matasilicate, $\mathrm{SrO} \cdot \mathrm{SiO}_{2}$, was mixed with enough water to form a paste, which was then packed into a vial and allowed to stand in a moist atmosphere for several days. No evidence of setting was observed. The orthosilicate, $2 \mathrm{SrO} \cdot \mathrm{SiO}_{2}$, behaved in the same manner, the only difference being that it became warm immediately on mixing with water. This may have been due to the presence of a little uncombined $\mathrm{SrO}$ in the preparation used. This experiment fails to support the statement of Zhuravlev [7] that $2 \mathrm{SrO} \cdot \mathrm{SiO}_{2}$ possesses hydraulic properties. Negative results were likewise obtained when the pastes were kept at steam-bath temperature. Subsequent microscopic examination failed to reveal any change in appearance. As shown in table 2, the anhydrous silicates also were unaffected by water at temperatures just below those at which they are formed hydrothermally.

The two anhydrous silicates were likewise unaltered after being shaken with an excess of water and allowed to stand 3 days at room temperature. Titration of the filtrates showed that a little strontium hydroxide had gone into solution, but the concentration was far less than the solubility of pure $\mathrm{Sr}(\mathrm{OH})_{2}$ at the same temperature.

A single solubility test at $30^{\circ} \mathrm{C}$ was made on each of the two hydrated silicates that were produced by boiling; namely, $3 \mathrm{SrO} \cdot 2 \mathrm{SiO}_{2} \cdot 4 \mathrm{H}_{2} \mathrm{O}$ and $3 \mathrm{SrO} \cdot 2 \mathrm{SiO}_{2}$. $3 \mathrm{H}_{2} \mathrm{O}$. The strontium hydroxide concentration was determined by titration after 1 day, and gravimetrically at the end of 10 weeks. There was no significant difference between the two values. The tetrahydrate residue was apparently unchanged during this period, and was in equilibrium with solution containing $0.745 \mathrm{~g}$ of $\mathrm{SrO}$ and $0.304 \mathrm{~g}$ of $\mathrm{SiO}_{2}$ per liter. For the purpose of comparison, the solubility of strontium hydroxide at the same temperature is about $10 \mathrm{~g}$ of $\mathrm{SrO}$ per liter. The trihydrate gave a solution of almost the same concentration, namely, $0.762 \mathrm{~g}$ of $\mathrm{SrO}$ and $0.303 \mathrm{~g}$ of $\mathrm{SiO}_{2}$ per liter, but in this case the solid residue had been partially converted to the compound tentatively designated $2 \mathrm{SrO} \cdot 2 \mathrm{SiO}_{2} \cdot 3 \mathrm{H}_{2} \mathrm{O}$, and the $\mathrm{SrO}: \mathrm{SiO}_{2}$ ratio in the residue had fallen to 1.26. Another sample of the trihydrate, kept in contact with water on the steam bath for 10 weeks, was completely converted to the same compound. The analysis of this material was the basis for the proposed formula. Progress of the transition was manifested by a curling of the acicular crystals, some of which developed a helical shape, as seen under the microscope.

The glass containers used for the solubility experiments were strongly attacked by the solution, especially at steam-bath temperature. This probably is the source of the additional silica required for the change from the $3: 2: 3$ to the $2: 2: 3$ compound.

\section{Relationship Between the Silicates of Strontium and Calcium}

It is of interest to consider possible relationships between the hydated silicates of strontium and those of calcium. The latter have been studied extensively by a number of investigators, including Flint, McMurdie and Wells [8], and the subject has recently been reviewed thoroughly by Taylor and Bessey [9].

If the oxide formulas of the strontium silicate hydrates described above are compared with a list of the reported calcium silicate hydrates, analogs will be noted for the $1: 1: 1,2: 2: 3,3: 2: 3,2: 1: 1$, and $3: 1: 2$ compounds. Whether any of these are actually isomorphous cannot be known without an analysis of the crystal structure. Visual comparison of the X-ray patterns of $3 \mathrm{SrO} \cdot 2 \mathrm{SiO}_{2} \cdot 3 \mathrm{H}_{2} \mathrm{O}$ and $3 \mathrm{CaO} \cdot 2 \mathrm{SiO}_{2} \cdot 3 \mathrm{H}_{2} \mathrm{O}$ (afwillite) reveals considerable similarity. The refractive indices, birefringence, and crystal form also indicate the possibility of a relationship between these two compounds. To a lesser extent, resemblances may be observed between the compound designated $2 \mathrm{SrO} \cdot 2 \mathrm{SiO}_{2} \cdot 3 \mathrm{H}_{2} \mathrm{O}$ and the mineral crestmoreite, for which the formula $2 \mathrm{CaO} \cdot 2 \mathrm{SiO}_{2} \cdot 3 \mathrm{H}_{2} \mathrm{O}$ has been given [8]. On the basis of refractive indices alone, it appears possible that the $1: 1: 1$ and $3: 1: 2$ strontium silicates may be related to the corresponding calcium silicates reported by Flint, McMurdie, and Wells [8]. In the case of the 2:1:1 compounds, the relationship, if any, is probably with the calcium silicate having a refractive index of 1.64 , sometimes designated the $\gamma$-hydrate. In these cases the data on crystal form are lacking, and the X-ray patterns are too complex for superficial comparison.

\section{Summary}

Hydrothermal treatment of mixtures of strontium hydroxide and silica gel in various proportions and at various temperatures produced seven hydrated strontium silicates, as well as the anhydrous metaand orthosilicates. Table 3 gives the probable compositions of the hydrates, and their optical properties, so far as the latter could be determined. The X-ray powder diffraction patterns, together with that of $\mathrm{SrO} \cdot \mathrm{SiO}_{2}$, are given in table 1 . Formulas given for the compounds having the oxide ratios $3: 2: 3$ and $3: 2: 4$ are believed to be correct, and the $2: 1: 1$ and $3: 1: 2$ formulas probably are correct, 
TABLE 3. Some optical properties of the strontium silicate hydrates

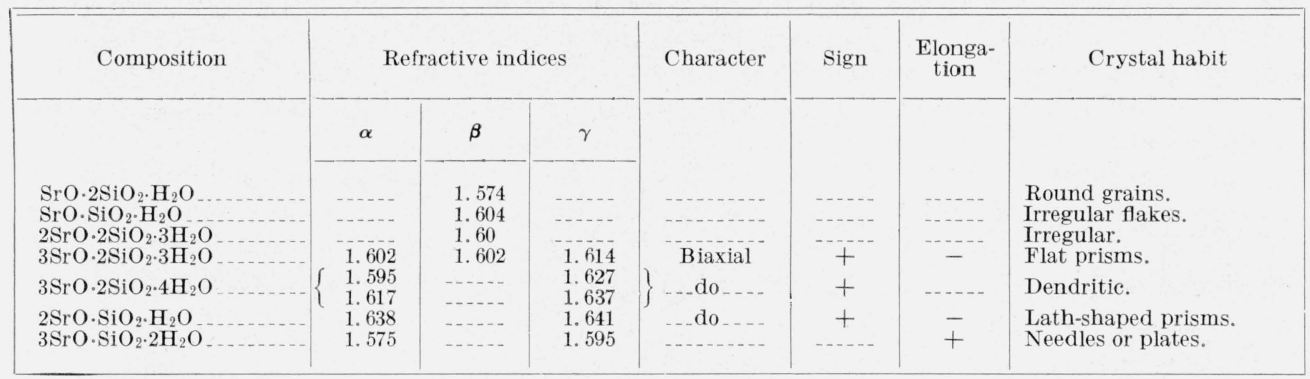

while the other 3 are somewhat in doubt. Both anhydrous compounds were formed hydrothermally at temperatures below $150^{\circ}$. The hydrates $3 \mathrm{SrO} \cdot 2 \mathrm{SiO}_{2} \cdot 3 \mathrm{H}_{2} \mathrm{O}$ and $3 \mathrm{SrO} \cdot 2 \mathrm{SiO}_{2} \cdot 4 \mathrm{H}_{2} \mathrm{O}$ were prepared at boiling temperature as well as under hydrothermal conditions.

The anhydrous silicates did not appear to be strongly attacked by water, and no evidence of hydraulic binding properties was found.

The X-ray patterns and photomicrographs were prepared by Barbara Sullivan and G. M. Ugrinic, thermal analyses were made by E. S. Newman, and many of the chemical analyses were performed by T. J. Chaconas. The writers are indebted to these people for their valuable assistance.

\section{References}

[1] E. P. Flint, H. F. McMurdie, and L. S. Wells, J. Research NBS 26, 13 (1941) RP1355.

[2] P. Eskola, Am. J. Sci. [5] 4, 331 (1922).

[3] H. O'Daniel and L. Tscheischwili, Z. Krist. 104, 348 (1942).

[4] R. Nacken, Zement 19, 818, 847 (1930).

[5] R. W. Nurse, J. Applied Chem. 2, 244 (1952).

[6] E. Jordis and E. H. Kantner, Z. anorg. Chem. 35, 82 (1903).

[7] V. F. Zhuravlev, Tsement, No. 8, 41 (1939).

[8] E. P. Flint, H. F. McMurdie, and L. S. Wells, J. Research NBS 21, 617 (1938) RP1147.

[9] H. F. W. Taylor and G. E. Bessey, Mag. Concrete Research (London) No. 4, 15 (1950).

Washington, May 21, 1953. 